Analytical Methods

\title{
Dynamic headspace solid-phase microextraction combined with one-dimensional gas chromatography-mass spectrometry as a powerful tool to differentiate banana cultivars based on their volatile metabolite profile
}

\author{
Marisela Pontes, Jorge Pereira, José S. Câmara* \\ Centro de Química da Madeira, Centro de Ciências Exactas e da Engenharia, Universidade da Madeira, Campus Universitário da Penteada, 9000-390 Funchal, Portugal
}

\section{A R T I C L E I N F O}

\section{Article history:}

Received 25 October 2010

Received in revised form 31 August 2011

Accepted 15 April 2012

Available online 21 April 2012

\section{Keywords:}

Banana cultivars

Solid-phase microextraction

1D-GC-qMS

Volatile organic metabolites

Multivariate analyses

\begin{abstract}
A B S T R A C T
In this study the effect of the cultivar on the volatile profile of five different banana varieties was evaluated and determined by dynamic headspace solid-phase microextraction (dHS-SPME) combined with one-dimensional gas chromatography-mass spectrometry (1D-GC-qMS). This approach allowed the definition of a volatile metabolite profile to each banana variety and can be used as pertinent criteria of differentiation. The investigated banana varieties (Dwarf Cavendish, Prata, Maçã, Ouro and Platano) have certified botanical origin and belong to the Musaceae family, the most common genomic group cultivated in Madeira Island (Portugal). The influence of dHS-SPME experimental factors, namely, fibre coating, extraction time and extraction temperature, on the equilibrium headspace analysis was investigated and optimised using univariate optimisation design. A total of 68 volatile organic metabolites (VOMs) were tentatively identified and used to profile the volatile composition in different banana cultivars, thus emphasising the sensitivity and applicability of SPME for establishment of the volatile metabolomic pattern of plant secondary metabolites. Ethyl esters were found to comprise the largest chemical class accounting $80.9 \%, 86.5 \%, 51.2 \%, 90.1 \%$ and $6.1 \%$ of total peak area for Dwarf Cavendish, Prata, Ouro, Maçã and Platano volatile fraction, respectively. Gas chromatographic peak areas were submitted to multivariate statistical analysis (principal component and stepwise linear discriminant analysis) in order to visualise clusters within samples and to detect the volatile metabolites able to differentiate banana cultivars. The application of the multivariate analysis on the VOMs data set resulted in predictive abilities of $90 \%$ as evaluated by the cross-validation procedure.
\end{abstract}

(c) 2012 Elsevier Ltd. All rights reserved.

\section{Introduction}

As aroma is one of the most appreciated fruit characteristics, volatile flavour compounds are likely to play a key role in determining the perception and acceptability of products by consumers. Identification of key volatile flavour metabolites that carry the unique character of the natural fruit is essential, as it provides the principal sensory identity and characteristic flavour of the fruit (Augusto, Valente, dos Santos Tada, \& Rivellino, 2000; Cheong et al., 2010; Navarro, De Lorenzo, \& Perez, 2004).

Banana (genus Musa of the Musaceae family) is one of the most important crops in the world. According to the Food and Agriculture Organization of the United Nations (FAO) statistics estimations (Arias, Dankers, Liu, \& Pilkauskas, 2003), the 10 major banana producing countries accounted for more than $75 \%$ of total banana production. Furthermore, India, China, the Philippines, Brazil and Ecuador alone produced more than $60 \%$ of total world bana-

\footnotetext{
* Corresponding author. Tel.: +351 291705112; fax: +351 291705149.

E-mail address: jsc@uma.pt (J.S. Câmara).
}

na production. World exports of bananas also show a high level of concentration, with developing countries accounting for the bulk of exports. Only Latin America and the Caribbean supplied, in average, about $70 \%$ of world exports. The four leading banana exporting countries in 2006 (Ecuador, Costa Rica, Philippines and Colombia) accounted for $64 \%$ of world exports with Ecuador alone provided more than $30 \%$ of global banana exports. From a consumer perspective, the most appealing features of banana are their flavour, nutrition or health aspects and convenience for consumption (Boudhrioua, Giampaoli, \& Bonazzi, 2003). Is a fruit of high nutritional value, very rich in sugar, minerals, mainly potassium (very important to regulate blood pressure), magnesium, phosphorous, calcium, sodium, vitamins (C, pyridoxine and riboflavin, mainly) and dietary fibres (helpful to regulate bowel movement). Their typical aroma is characterised by the presence of a wide range of volatile metabolites, with different volatilities and concentrations, that can vary among the different cultivars, as the initial work of Cano and collaborators with Spanish and Columbian Enana cultivars showed (Cano et al., 1997). This volatiles belong to distinct chemical classes mainly ethyl esters (Jordan, Tandon, Shaw, \& Goodner, 2001) and, 
to a lesser extent carbonyl compounds, monoterpenoids, $\mathrm{C}_{13}$-norisoprenoids and furan compounds. According to Tressl et al., (Tressl \& Albrecht, 1985) although the acetates and butyrate esters are the most abundant in bananas, some 3-methylbutyrate esters, 2-methylpropionates and caproates are also produced in minor accounts. Acetates are of particular importance due to their high concentrations and low odour thresholds. The biosynthetic pathway for their formation in ripening climacteric fruits is well-established (Wyllie \& Fellman, 2000; Yoshioka, Ueda, \& Iwata, 1982). They are biosynthesized from long-chain fatty acid metabolism or formed by a complex group of chemical substances (e.g. aldehydes, alcohols, ketones, esters, lactones, terpenes), with a usually low concentration $(\mu \mathrm{g} / \mathrm{L})$ and can be affected by a number of agronomical (variety, climatic conditions, ripening stage of the fruit) and technological (harvest, post-harvest, treatments, storage and processing conditions) factors. However, these factors control the quantitative and qualitative composition of the ester profile, which in many cases determine the character and perceived quality of the fruits (Brat et al., 2004). Fruit esters also are formed by the reaction between alcohols and acyl CoA's derived from both fatty acid and amino acid metabolism and are catalysed by the enzyme acyl alcohol transferase (ATT) (Tressl \& Drawert, 1973).

Boudhrioua et al. (2003) showed that 3-methylbutyl acetate, 3-methylbutyl butyrate and 3-methylbutyl-3-methyl butyrate, isoamyl acetate, pentan-2-one and isoamyl butyrate are characteristics of the geographic origin of the fruit. In addition, fatty acids, generated by the oxidative degradation of linoleic and linolenic acids, contribute to ester biosynthesis in fruit. Degradation of fatty acids results in the production of volatile aldehydes, which in turn are utilised by alcohol dehydrogenases generating alcohols, aldehydes and branched/aromatic aliphatic acids. These compounds contribute, and in some cases are determining, to the primary aroma of many fruits (Perez, Olias, Luaces, \& Sanz, 2002). Moreover, some volatiles are particularly good indicators of the ripening stage of bananas. This is the case of hexanal and (E)-2-hexenal, characteristic of riped bananas, and isobutyl acetate and isopentyl acetate, more abundant in ripening bananas (Mayr, Märk, Lindinger, Brevard, \& Yeretzian, 2003).

Increasing consumer demand for safety and nutritional excellence together with higher market competition underlines the importance of food analysis. This drives a need for analysts to develop rapid, reliable, less labour-consuming, and more accurate analytical procedures. However, this is a daunting task as food stuffs contain a broad range of components. In the fruit-producing or -processing industry, good analytical methods are crucial to the success of any quality control during storage, processing, and/or product development studies. The most typically used methods for extraction and pre-concentration are headspace techniques, purge-andtrap, liquid-liquid extraction, and simultaneous distillation and extraction. The majority of these methods present some drawbacks, such as the possibility of sample contamination, loss of analytes during the concentration step, it requires large amounts of toxic and expensive solvents that can be harmful to the operator and to the environment, are time-consuming and usually offers low recoveries.

Considering the limitations of the traditional sampling techniques, headspace solid-phase microextraction (HS-SPME) emerges as an attractive alternative (Augusto et al., 2000). It is a solvent-free sample preparation technique that integrates sampling, isolation/extraction and concentration into a single uninterrupted process, resulting in high sample throughput (Mendes, Gonçalves, \& Câmara, 2012). Seems particularly appealing since it also eliminates problems associated with chemically and thermally unstable samples where generation of artefacts can be problematic. However, presents some disadvantages since (i) it works by equilibration thus gives incomplete recoveries; (ii) it only allows measurement of what partitions into the fibre phase; and (iii) it's partitioning is highly dependent on matrix. Nevertheless, its simplicity of use and fibre reusability had made SPME an attractive choice for many analytical applications (Coelho et al., 2008; Ferreira, Perestrelo, Caldeira, \& Camara, 2009; Ibáñez, López-Sebastián, Ramos, Tabera, \& Reglero, 1998; Perestrelo, Nogueira, \& Camara, 2009). In particular in combination with GC-MS, this technique have been largely used in environmental (Ternes, 1998), food (Camara, Alves, \& Marques, 2006; Cheong et al., 2010; Pereira, Pereira, \& Câmara, 2011; Pozo, Pueyo, Martin-Alvarez, \& Polo, 2001), forensic (Chien, Uang, Kuo, Shih, \& Jen, 2000; Kumazawa, Lee, Sato, \& Suzuki, 2003), pharmaceutical and biomedical (Deng, Li, \& Zhang, 2004a; Deng, Zhang, \& Li, 2004b; Silva, Passos, \& Câmara, 2011, 2012) coffee (Risticevic, Carasek, \& Pawliszyn, 2008) and biological (Moeder, Schrader, Winkler, \& Popp, 2000) analysis.

The aim of the current research study is dedicated towards the development a simple, robust, reliable and solvent-free technique, without sample derivatization, based on the dHS-SPME combined with 1D-GC-qMS, in order to allow a qualitative and semi-quantitative screening of a broad range of VOMs in banana from different cultivars: Dwarf Cavendish, Prata, Maçã, Ouro and Platano, growing at Madeira Island (Portugal), which could be used as cultivar markers. The main qualitative and semi-quantitative differences were established. In a previous step this work focuses on optimisation of the most influencing factors of the dHS-SPME. The optimised method will be then applied to the analysis of real banana samples, after which the acquired data will be submitted to PCA statistical evaluation to establish an objective comparison among banana from different cultivars. To the best of our knowledge this is the first paper reporting the volatile composition of Prata (Musa balbisiana), Ouro (Musa paradisiaca), Maçã (Musa acuminate) and Platano (Musa paradisiaca) banana varieties growing at Madeira Island, as well as the first paper reporting differentiation among banana cultivars based on their volatile metabolomic profile.

\section{Material and methods}

\subsection{Chemicals and sample preparation}

All chemicals used were analytical quality and all solvents were HPLC grade. Sodium chloride (99.5\%) used to adjust the ionic strength (decrease the solubility of the VOMs which then partition more readily into the headspace improving the adsorption of analytes by coating), was supplied by Merck (Darmstadt, Germany). Deionised water was obtained from Milli-Q water purification system (Millipore, Bedford, PA, USA). The $n$-alkanes mixture containing $\mathrm{C}_{8}-\mathrm{C}_{20}$ straight-chain alkanes in hexane, and the internal standard, octan-3-ol, were purchased from Sigma-Aldrich (Spain). Helium, ultra-pure grade (Air Liquide, Portugal) was used as carrier gas in the GC system. The SPME fibre optimisation step was carried out by testing commercially available silica SPME fibres purchased from Supelco (Bellefonte, PA, USA) and coated with the following polymers: polydimethylsiloxane (PDMS, $100 \mu \mathrm{m}$ ), polyacrylate (PA, $85 \mu \mathrm{m})$, divinylbenzene/carboxen on polydimethylsiloxane (DBV/CAR/PDMS; StableFlex, 50/30 $\mu \mathrm{m}$ ), carboxen/polydimethylsiloxane (CAR/PDMS, $75 \mu \mathrm{m}$ ) and polydimethylsiloxane/ divinylbenzene (PDMS/DVB, $65 \mu \mathrm{m}$ ). Prior to their first use, all fibres were conditioned according to the manufacturer's instructions by heating in the injection port of the GC. Before the initial application, blank runs were completed before each sampling to ensure no carry-over of analytes from the previous extraction. Clear glass screw cap vials for SPME with PTFE/silica septa were purchased from Supelco.

Three sets of $250 \mathrm{~g}$ of mature banana fruits (Musa acuminate L.) from Dwarf Cavendish (DC), Prata (BP), Ouro (BO), Maçã (BM) and Platano $(\mathrm{P})$ cultivars growing at Madeira Island (Portugal) were obtained from commercial sources, at green stage, and kept at 
room temperature during maturation. Fruits were selected at random, carefully hand-peeled, sliced and pureed at room temperature for $2 \mathrm{~min}$ in a blender to obtain a homogeneous paste. A small volume $(1.5 \mathrm{~mL})$ of methanol was sprayed onto the paste in order to avoid subsequent enzymatic activity. The banana puree was placed into glass vials and stored at $-20{ }^{\circ} \mathrm{C}$ until analysis. All experiments and analytical determinations were carried out at least in triplicate.

\section{2. dHS-SPME procedure}

The handling of an SPME device is simple, and the analysis of volatile metabolites could be easy. However, the process becomes complex while analyzing sample matrices of heterogeneous nature. The complexity also increases depending upon the nature of compounds to be extracted and matrix. Therefore, careful selection and optimisation of extraction parameters have to be undertaken to improve the sensitivity and the reproducibility of this method.

For this particular optimisation experiment Dwarf Cavendish banana was selected as the matrix. The analysis were carried out by placing $0.5 \mathrm{~g}$ portions of banana puree, previously homogenised, diluted with $1 \mathrm{~mL}$ ultra-pure water (Milli-Q) in a $4 \mathrm{~mL}$ headspace glass vial covered with a PTFE/silicone septum and containing a micro stirring bar (Supelco). As stirring of the solution usually improves the extraction, because the static layer resistant to mass transfer is destroyed (facilitate mass transport between the bulk of the aqueous sample and the fibre), all the experiments were performed under constant stirring velocity $\left(750 \mathrm{~min}^{-1}\right)$. After the addition of $0.3 \mathrm{~g}$ of $\mathrm{NaCl}$, in order to improve the extraction efficiency by decreasing the solubility of hydrophilic metabolites in the aqueous phase and $1 \mu \mathrm{L}$ of internal standard (octan-3-ol, $4.22 \mathrm{mg} / \mathrm{L}$ ), the vials were immersed in a thermostat bath maintained at the temperature selected for the extraction. Afterwards the SPME fibres were manually inserted into the headspace over the samples. In search of optimised conditions the (i) nature of the fibres; (ii) the exposure time $(10-80 \mathrm{~min})$ of the fibre to the headspace, and (iii) the extraction temperature, were tested and evaluated.

After exposition period, the SPME fibres were withdrawn into the needle, removed from the glass vial and immediately inserted into the injection port of the gas chromatograph where the extracted metabolites were thermally desorbed for 6 min and transferred directly to the analytical column. Desorption temperatures, depending on the fibre used, $250{ }^{\circ} \mathrm{C}$ for PDMS/DVB, PDMS and StableFLex, $260{ }^{\circ} \mathrm{C}$ for PA and $300^{\circ} \mathrm{C}$ for CAR/PDMS coating.

\subsection{Selection of fibre coating}

The polarity and volatility characteristics of the target metabolites are the primary issues addressed before selecting a fibre coating. The most commonly used fibre coatings are: $100 \mu \mathrm{m}$ PDMS; $65 \mu \mathrm{m} \mathrm{DVB/PDMS} ; 75 \mu \mathrm{m}$ CAR/PDMS; and $85 \mu \mathrm{m}$ PA. Polydimethylsiloxane (PDMS) is the most widely used coating. The main advantage of using this coating is its ability to withstand high temperatures, up to about $300^{\circ} \mathrm{C}$ and its greater stability than CAR/ PDMS and DVB/PDMS coatings. Another advantage of this fibre coating is its possibility of estimating the distribution constants for organic compounds from retention times on PDMS-coated GC columns.

In this step the extraction efficiency of five SPME fibres (Supelco, Bellefonte, USA), with different stationary phases and various film thicknesses, was evaluated and compared. The extraction procedure is described in the above section. The extraction procedures were carried out at $50{ }^{\circ} \mathrm{C}$ for $40 \mathrm{~min}$ of exposure fibre (on all five fibres). The analytes, being characterised by different volatilities and polarities, were selected across the GC chromatogram and the total sum of their peak areas was used to select the SPME coating having best performance characteristics. The $65 \mu \mathrm{m}$ PDMS/DVB coating fibre was found to give the best performance for the whole range of banana VOMs. Therefore this fibre was used in all further experiments. At least four replicates were done for each coating fibre.

Different fibre coatings used influenced the chemical nature of the extracted metabolite depending on their characteristic polarity and volatility. In order to evaluate the effect of the nature of the fibre on the extraction efficiency of VOMs from bananas by dHSSPME, and taking account the physical/chemical characteristics of the targets under consideration, a set of five coating fibres (CAR/PDMS, PDMS/DVB, PDMS, PA and StableFlex), covering a wide range of polarities and mechanisms, were used among those most routinely used for assaying volatiles. Each fibre was exposed to the headspace for the same time $(40 \mathrm{~min})$ at the same temperature $\left(50^{\circ} \mathrm{C}\right)$. Blank runs were conducted between extractions with the chosen fibre, to check for absence of carry-over which would cause memory effects and misinterpretation of results. All tests were carried out using the same banana cultivar (Dwarf Cavendish). The comparison of the SPME fibre performance was made in terms of extraction efficiency, number of identifiable metabolites in the extract and reproducibility.

\subsection{Selection of extraction time and temperature}

The extraction time profile was initially constructed at the extraction temperature of $50{ }^{\circ} \mathrm{C}$ with $10,20,40,60$ and 80 min of analysis isolation. An optimal extraction time of $60 \mathrm{~min}$ was selected for further studies. To select the temperature which gives the highest extraction efficiency, another experiment was carried out. A range of four different temperatures, 30, 40, 50 and $60{ }^{\circ} \mathrm{C}$ were tested using $60 \mathrm{~min}$ of analyses extraction. A temperature of $50{ }^{\circ} \mathrm{C}$ was selected. Desorption time was $6 \mathrm{~min}$ and the GC liner temperature varied according to fibre coating (Section 2.2).

\subsection{D-GC-MS analyses}

The desorbed volatile metabolites were analysed in an Agilent Technologies 6890N Network gas chromatograph system (Palo Alto, CA, USA) equipped with a $30 \mathrm{~m} \times 0.25 \mathrm{~mm} \mathrm{I.D.,} \mathrm{with} \mathrm{a}$ $0.25 \mu \mathrm{m}$ film thickness, BP-20 fused silica capillary column, and interfaced with an Agilent 5975 quadrupole inert mass selective detector. Helium (Helium N60, Air Liquid, Portugal) was used as carrier gas at a flow rate of $1 \mathrm{~mL} / \mathrm{min}$ (column-head pressure: $89.6 \mathrm{kPa}$ ). The injector was operated in the splitless mode. The GC oven temperature program was set at an initial value of $40^{\circ} \mathrm{C}$ ( $1 \mathrm{~min}$ hold); increased to $150{ }^{\circ} \mathrm{C}$ at $2.5^{\circ} \mathrm{C} / \mathrm{min}$, then raised to $220^{\circ} \mathrm{C}$ at $15^{\circ} \mathrm{C} / \mathrm{min}$ and hold for $5 \mathrm{~min}$ (total GC run time of $54 \mathrm{~min}$ ).

For the 5975 MS system, the temperatures of the transfer line, quadrupole and ionisation source were 270,150 and $230{ }^{\circ} \mathrm{C}$ respectively; electron impact mass spectra were recorded at $70 \mathrm{eV}$ ionisation voltages and the ionisation current was $10 \mu \mathrm{A}$. The acquisitions were performed in Scan mode $(35-300 \mathrm{~m} / \mathrm{z}$ ). The electron multiplier was set to the auto tune procedure. Agilent MS ChemStation Software, equipped with a NIST05 mass spectral library was employed for identification of the volatile metabolites extracted from real samples. A series of $C_{8}-C_{20} n$-alkanes were analysed by dHS-SPME $/{ }^{1} \mathrm{D}-\mathrm{GC}-\mathrm{qMS}$ to establish the retention indices (RI), in order to tentatively identify the compounds by comparison with the literature. The relative amounts of individual metabolites are expressed as percent peak areas relative to the total peak area $\left(\operatorname{RPA}(\%)=A_{i} / \Sigma A_{i} \times 100\right)$, where $A_{i}$ is the GC peak area of $i$ metabolite. 
Identification of volatile metabolites was achieved by: (1) comparison of the mass spectrometric data and chromatographic retention of authentic standards, when available, (2) comparison the Kovats retention index (RI) value, which was determined according to the Van den Dool and Kratz RI equation (Van Den Dool \& Kratz, 1963), and (3) similarity of mass spectrometric data. As generated by the NIST, 2005 software (Mass Spectral Search Program V.2.0d; NIST 2005, Washington, DC). For the determination of the RI, a $\mathrm{C}_{8}-\mathrm{C}_{20} n$-alkanes series was used, and the values were compared, when available, with values reported in the literature for similar chromatographic columns (Bianchi, Careri, Mangia, \& Musci, 2007; Brat et al., 2004; Hognadottir \& Rouseff, 2003). More than 60 VOMs distributed by different chemical groups were identified to profile the global signature of the banana cultivars under study. In order to evaluate quantitative differences in the aromatic profile of the samples investigated, GC peak areas were calculated as total ion current for all the analytes.

\subsection{Statistical analysis}

Significant differences among banana cultivars were determined by one-way analysis of variance (Anova) using a SPSS Program, version 16.0 (SPSS Inc., 2008). Principal component analysis (PCA) was performed using the same SPSS program. This technique was applied to the normalised total peak areas from different chemical classes.

Principal component analysis (PCA) is an unsupervised technique that reduces the dimensionality of the original data matrix retaining the maximum amount of variability (Forina, Armanino, Castino, \& Ubigli, 1986), allowing the visualisation of the different banana cultivars in a two-dimensional space and identifying the directions in which most of the information is retained. It is therefore possible to explain the differences between several cultivars by means of factors obtained from the data sets and, at the same time, to determine which variables contributed the most for such differences.

Stepwise linear discriminant analysis (SLDA) probably the most widely applied supervised pattern recognition method, searches for directions (discriminant functions) which achieve maximum separation among categories by maximising between the class variance relative to the within-class variance. SLDA renders a number of orthogonal linear discriminant functions equal to the number of categories minus one. This method minimises the variance within categories and maximises the variance between categories (Powers \& Keith, 1968). The variables included in the analyses are determined with a stepwise-LDA using a Wilk's Lambda as a selection criterion and an $F$ statistic factor to establish the significance of the changes in Lambda when a new variable is tested. The prediction capacity of the discriminant models was studied by "cross-validation" in order to determine the stability of the model.

\section{Results and discussion}

The sequence followed in this study consisted of two steps. The first focused on obtaining the best experimental conditions to extract VOMs from banana of different cultivars by dHS-SPME procedure combined with 1D-GC-qMS. In the second step an objective comparison among the investigated banana cultivars has been established in terms of qualitative and semi-quantitative differences on volatile composition by using the optimised conditions. Different volatile patterns were observed according to banana cultivars. Among other metabolite classes, ethyl esters, acetates, isoamyl esters, alcohols and phenols, were identified.

\subsection{Optimisation of SPME conditions}

To optimise dHS-SPME method some parameters controlling the performance of the extraction efficiency were taken into account. This process has been conducted by considering one parameter at a time keeping all other variables constant (univariate experimental design).

\subsection{Evaluation of the fibre}

The nature of the fibre is an important aspect for the pre-concentration of the VOMs in Dwarf Cavendish banana since each fibre shows a different extraction profile. The volatile compounds identified using the five fibres on the same Dwarf Cavendish sample, in rigorously reproduced temperature and exposure time conditions and the relative extraction efficiencies of the tested fibres are summarised in Table 1.

Altogether 64 VOMs were extracted and identified on the basis of their mass spectra (MS) and retention indices (RI) (Table 1). These included ethyl esters, isoamyl esters, acetates, higher alcohols, ketones and phenols. The qualitative composition of banana volatiles and the number of identified metabolites using the five fibres under study is very different (Table 1 ).

A comparison among the fibre's performance is relative since it would have to be performed in the optimised conditions to each fibre. Nevertheless, among the five fibres, it clearly shows (Fig. 1a) that the semi-polar PDMS/DVB fibre, made of a mixture of solid DVB polymers coated with a PDMS liquid polymeric film, exhibited the highest efficiency in the extraction process of the banana VOMs, extracting around three times more than PA and PDMS, and around 1.5 times more than StableFlex and CAR/PDMS fibres. Similar amounts of volatiles (30.8-34.2\%) were extracted by PDMS and PA fibres coating while 66.1-71.6\% were extracted when using CAR/PDMS and StableFlex coatings. Based on the data evaluation completed within this particular optimisation experiment, PDMS/ DVB fibre provided the best sensitivity in terms of total compound peak areas, number of isolated metabolites (51) and high reproducibility (lower than 7\%), and therefore was utilised in all further optimisation/real analyses experiments.

Fig. 1b, illustrated that the fibres show different selectivity to volatile metabolites. PDMS/DVB coating have a larger affinity for ethyl esters (EE), furan compounds (FUR) and norisoprenoids/monoterpenoids/sesquiterpenoids (NMS) compounds. CAR/PDMS fibre shown to be relevant for the extraction of carbonyl compounds (CC) whereas StableFlex coating affords a higher extraction for higher alcohols (HA). According to Fig. 1b, independent of the employed fibre, ethyl esters (EE) showed the most intense signals which suggest that ethyl esters might be VOMs with higher concentrations.

\subsection{Influence of extraction temperature and time}

The extraction temperature and the exposure time of the fibre to the headspace are two important factors that control sample recovery by the fibres and consequently, must be studied in order to establish the optimum extraction conditions.

Temperature is an important parameter for the SPME extraction process. Since extraction by this methodology is an exothermic process, it controls the diffusion rate of the analytes into the fibre coating. As the temperature increases, diffusion coefficients and Henry's constants increase while partition coefficients to the extraction phase decrease, because diffusion coefficients increase, the time required to reach equilibrium decreases. Finally, due to the lower partition coefficients to the extraction phase, the equilibrium amount decrease (Lambropoulou \& Albanis, 2001; Perestrelo, Caldeira, Rodrigues, \& Camara, 2008). To check the effect of 
Table 1

Comparison of the relative extraction efficiencies of different SPME coatings for VOMs extraction from Dwarf Cavendish cultivar.

\begin{tabular}{|c|c|c|c|c|c|c|c|c|}
\hline \multirow[t]{2}{*}{ Peak number } & \multirow[t]{2}{*}{$\mathrm{RT}^{\mathrm{a}}(\min )$} & \multirow[t]{2}{*}{$\mathrm{RI}^{\mathrm{b}}$} & \multirow[t]{2}{*}{ Metabolite } & \multicolumn{5}{|c|}{ SPME fibre type } \\
\hline & & & & $\mathrm{PDMS} \mathrm{DVB}^{\mathrm{C}}$ & PDMS & PA & StableFlex & CAR/PDMS \\
\hline \multirow[t]{2}{*}{2} & 2.408 & 906 & Ethyl acetate & 25 & 8 & - & 38 & 100 \\
\hline & 2.656 & 928 & 3-Methyl-butanal & & 100 & & & \\
\hline 3 & 3.333 & 979 & Pentan-2-one & 83 & 15 & 23 & 73 & 100 \\
\hline 4 & 3.882 & 1013 & Isobutyl acetate & 100 & 20 & 20 & 44 & 31 \\
\hline \multirow[t]{2}{*}{5} & 4.287 & 1035 & Ethyl butyrate & 100 & 18 & & 51 & 84 \\
\hline & 4.997 & 1070 & Butyl acetate & 100 & 34 & 22 & 67 & 81 \\
\hline 8 & 5.206 & 1079 & Hexanal & 85 & 32 & 21 & 100 & - \\
\hline \multirow[t]{2}{*}{9} & 5.399 & 1087 & 2-Methyl-2-methylpropyl propanoate & 97 & - & - & 100 & - \\
\hline & 5.677 & 1098 & 2-Methyl propan-1-ol & 100 & - & - & 88 & - \\
\hline 10 & 6.258 & 1120 & Isoamyl acetate & 100 & 35 & 25 & 58 & 42 \\
\hline \multirow[t]{3}{*}{11} & 6.569 & 1131 & Pentan-2-ol & - & - & - & - & 100 \\
\hline & 6.971 & 1144 & Butyl isobutyrate & 100 & - & - & - & - \\
\hline & 7.062 & 1147 & Butan-1-ol & 68 & - & - & - & 100 \\
\hline \multirow[t]{3}{*}{12} & 7.386 & 1157 & 2-Methylpropyl butyrate & 100 & 20 & 22 & 57 & 38 \\
\hline & 7.925 & 1173 & 2-Methyl-2-methylpropyl butyrate & 100 & - & - & 51 & 46 \\
\hline & 8.135 & 1179 & Heptan-2-one & 100 & - & - & 66 & 86 \\
\hline 14 & 8.481 & 1188 & Isoamyl butyrate & 100 & - & - & 44 & 28 \\
\hline \multirow[t]{3}{*}{16} & 8.582 & 1191 & 2-Methyl-3-methylbutyl propanoate & 100 & - & - & - & - \\
\hline & 8.635 & 1192 & 4-Methyl heptane & - & - & - & 100 & - \\
\hline & 8.716 & 1194 & 2,3-Dimethyl hexane & - & - & 100 & - & - \\
\hline 18 & 9.142 & 1204 & 3-Methylbutan-1-ol & - & 21 & - & 100 & - \\
\hline 19 & 9.334 & 1206 & 1-Methylbutyl butyrate & 100 & 11 & - & - & - \\
\hline 21 & 9.494 & 1209 & Butyl butyrate & 37 & 10 & 10 & 28 & 100 \\
\hline & 10.017 & 1216 & 2-Methylpentyl butyrate & 100 & - & - & - & - \\
\hline & 10.720 & 1226 & Isoamyl butyrate & 5 & 100 & - & 2 & 2 \\
\hline & 10.841 & 1228 & 5-Hepen-2-one & & & & & \\
\hline & 11.385 & 1235 & 2-Methyl-3-methylbutyl propanoate & - & - & 50 & - & 100 \\
\hline 25 & 11.394 & 1236 & 3-Methylbutyl butyrate & 100 & - & - & 79 & - \\
\hline 26 & 11.746 & 1239 & Hexyl acetate & 100 & 33 & 21 & 66 & 79 \\
\hline 28 & 11.920 & 1241 & 2-Methyl-3-methylbutyl butyrate & 100 & 39 & 34 & 87 & 66 \\
\hline 30 & 12.730 & 1251 & 3-Methyl-3-methylbutyl butyrate & 100 & 43 & 24 & 83 & 51 \\
\hline & 13.335 & 1258 & (Z)-4-hexen-1-yl acetate & - & 100 & - & - & - \\
\hline 31 & 13.544 & 1260 & 3-Hepten-1-yl acetate & 100 & - & - & - & - \\
\hline & 14.459 & 1269 & (E)-3-methyl-1,3-pentadiene & - & - & - & 100 & - \\
\hline 32 & 14.865 & 1273 & (E)-4-hexen-1-yl acetate & 100 & - & - & 62 & 12 \\
\hline 33 & 15.466 & 1279 & Hexan-1-ol & 100 & 54 & 38 & 97 & 68 \\
\hline & 15.469 & 1279 & 4-Methyl pentan-1-ol & 100 & - & - & - & - \\
\hline & 15.731 & 1281 & 3-Methylbutyl pentanoate & 100 & - & - & 99 & - \\
\hline & 17.999 & 1402 & (E)-2-hexen-1-ol & 100 & - & - & 154 & - \\
\hline 36 & 18.343 & 1410 & Hexyl butyrate & 100 & 38 & - & 87 & 82 \\
\hline & 18.890 & 1424 & (Z)-4-hexen-1-ol & - & 100 & - & - & - \\
\hline & 18.986 & 1424 & (E)-3-hexen-1-ol & 93 & - & - & 100 & 71 \\
\hline & 19.791 & 1442 & 3-Methylhexyl butyrate & 100 & 47 & 33 & 86 & 81 \\
\hline 37 & 19.987 & 1446 & (Z)-2-Methyl cyclohexyl butyrate & 100 & 47 & - & 83 & 82 \\
\hline 38 & 20.428 & 1455 & Isopentyl hexanoate & 100 & 50 & - & 90 & 55 \\
\hline & 20.621 & 1459 & Acetic acid & - & - & - & - & 100 \\
\hline & 20.627 & 1459 & Furfural & 100 & - & - & - & - \\
\hline 40 & 21.791 & 1482 & 4-Hexen-1-yl butyrate & 100 & 36 & 33 & 79 & 68 \\
\hline 41 & 22.794 & 1500 & Ethenyl cyclohexane & 100 & 33 & 35 & 68 & 77 \\
\hline & 23.504 & 1516 & Heptan-4-one & 14 & - & 23 & 100 & 48 \\
\hline & 23.729 & 1521 & 2-Methylbutyl isobutyrate & 100 & - & - & 77 & 65 \\
\hline 45 & 25.553 & 1559 & Cycloocta-1,3-diene & 100 & - & - & - & 53 \\
\hline & 25.592 & 1560 & 3-Ethenyl cyclohexene & - & 100 & - & - & - \\
\hline 46 & 27.312 & 1594 & 3-Methyl bicyclo[4.1.0]heptane & 100 & - & - & - & - \\
\hline & 27.763 & 1603 & Hexyl hexanoate & - & 100 & - & - & - \\
\hline 47 & 28.439 & 1618 & 2-Methyl-1-methyl butyl propanoate & 100 & - & - & - & 39 \\
\hline 48 & 32.414 & 1702 & 2-Methyl ethyl propanoate & 100 & - & - & - & - \\
\hline & 34.890 & 1759 & 2-Methyl-1-nonen-3-one & 100 & - & - & - & - \\
\hline & 46.312 & 2028 & Octanoic acid & 100 & - & - & - & - \\
\hline 50 & 46.430 & 2030 & 5-Hydroxymethylfurfural & 100 & - & - & - & - \\
\hline 51 & 46.717 & 2037 & 1,3-Dihydroxypropan-2-one & 100 & - & - & - & - \\
\hline & 47.907 & 2063 & Eugenol & 100 & - & - & - & 15 \\
\hline 52 & 48.695 & 2080 & Elemicin & 100 & 44 & 85 & 48 & 48 \\
\hline 53 & 49.156 & 2090 & $\mathrm{DDMP}^{\mathrm{d}}$ & 100 & - & 81 & - & - \\
\hline Total compou & er fibre & & & 51 & 28 & 19 & 36 & 34 \\
\hline
\end{tabular}

a Retention time.

b Experimentally determined retention indices on the BP-20 column, relative to $C_{8}-C_{20}$ hydrocarbons.

c The extraction efficiency of the PDMS/DVB fibre was set as $100 \%$.

d DDMP: 2,3-dihydro-3,5-dihydroxy-6-methyl-4H-pyran-4-one. 

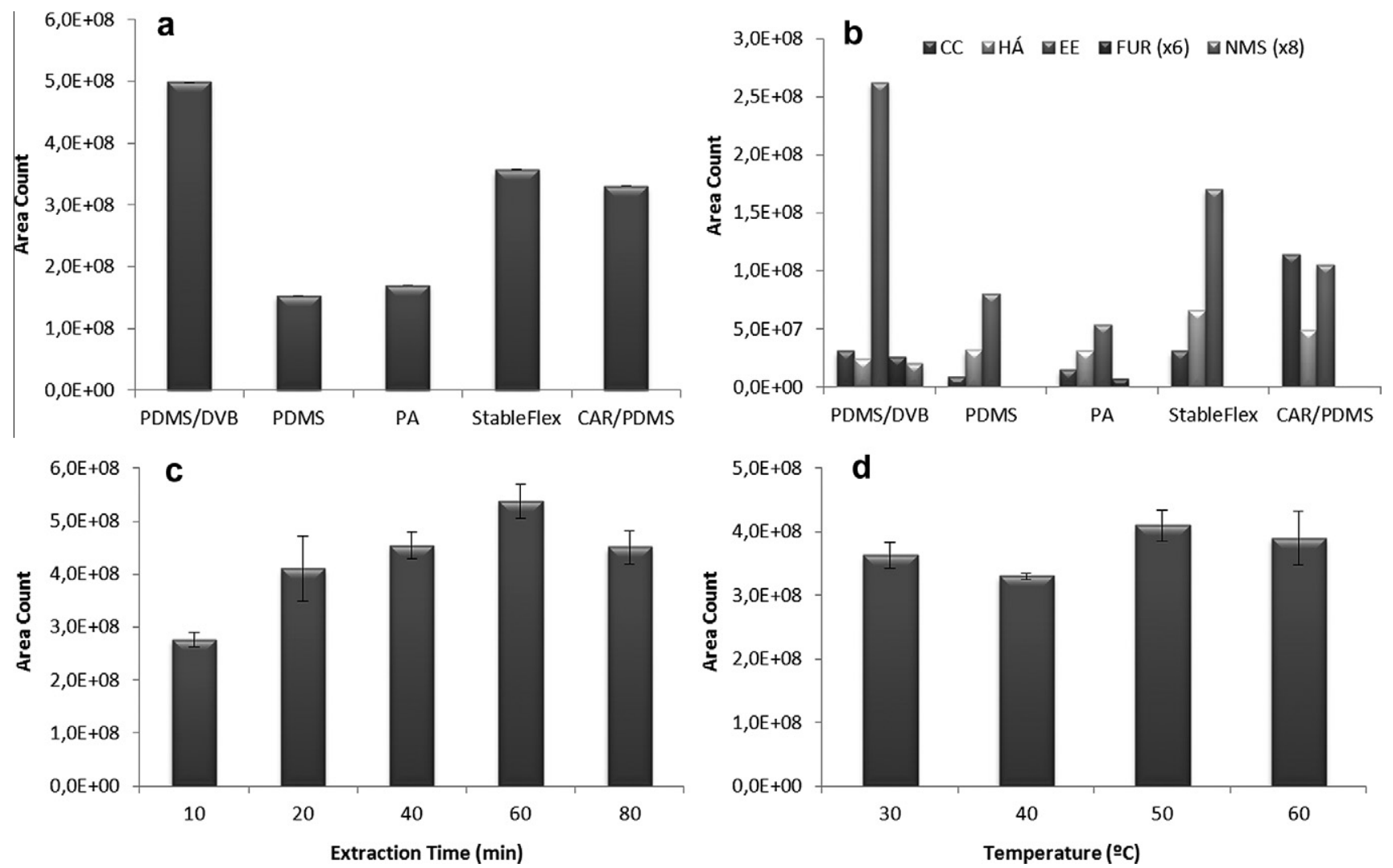

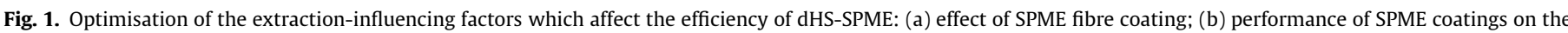

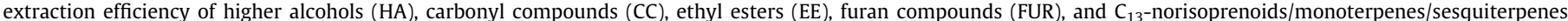

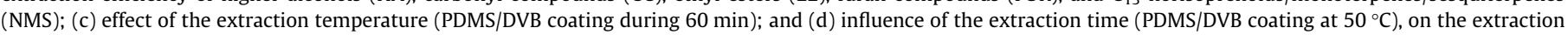
efficiency of VOMs from Dwarf Cavendish bananas. Error bars represent standard error of the mean ( $n=4$ for each data point).

extraction temperature on SPME extraction efficiency, PDMS/DVB fibre was exposed to the headspace at four different temperatures $30,40,50$ and $60^{\circ} \mathrm{C}$, for $60 \mathrm{~min}$. The results of triplicate experiments are summarised in Fig. 1c. In general, as the temperature increases, the recovery of volatile compounds improves, since heating of solid samples help to release analytes into the headspace and facilitate the SPME process. The best recovery of volatiles was obtained at $50{ }^{\circ} \mathrm{C}$.

The time that the fibre was in contact with the headspace of the sample, had a significant effect on the chromatographic peak areas of the extracted metabolites, as is apparent from Fig. 1d. The adsorption time was evaluated by exposing the fibre into the headspace between 10 and $80 \mathrm{~min}(10,20,40,60$ and $80 \mathrm{~min})$ at $50{ }^{\circ} \mathrm{C}$. The influence of the fibre exposure time on the yield of microextraction is displayed in Fig. 1d.

For most metabolites the extraction efficiency increased with the extraction time, during the first $60 \mathrm{~min}$ of the fibre exposure decreasing thereafter (Fig. 1d). An exposure time of $60 \mathrm{~min}$ was chosen because fibre exposure times longer than $60 \mathrm{~min}$ were too long and the differences in response between 60 and $80 \mathrm{~min}$ were less than $10 \%$. Taking these results into account the best results were obtained using an extraction time of $60 \mathrm{~min}$ at $50{ }^{\circ} \mathrm{C}$.

\subsection{Analyses of volatile metabolites in different banana cultivars}

The optimised technique was applied to different banana cultivars taken from commercial sources. Each banana sample was analysed four times using the optimised extraction conditions described above (PDMS/DVB fibre; $50{ }^{\circ} \mathrm{C} ; 60 \mathrm{~min}$; salt addition with continuous stirring). A typical total ion current (TIC) chromatogram of the volatile constituents from different banana varieties extracted by dHS-SPME is shown in Fig. 2. The technique used made it possible to identify 68 VOMs in the investigated banana cultivars.

The identified volatile metabolites are shown in Table 2 where are listed in order of their elution on the BP-20 column together with their retention indices and percentage of relative area. Most of the volatile metabolites were tentatively identified by a library search NIST05. In some cases a comparison with authentic compounds was performed. The retention indices were calculated for each peak and compared with the literature in order to ensure the correct identification of the metabolites. Table 2 summarises the average $(n=4)$ relative composition observed in the headspace of bananas from different cultivars studied. As previously reported to the common export banana cultivar Gran Enano, there is a great diversity in the aroma composition of bananas in different ripening stages and even in bananas in the same ripening stage treated or not with ethylene (Vermeir, Hertog, Vankerschaver, Swennen, Nicolaï, \& Lammertyn, 2009).

The relative composition of each flavour compound was calculated as the percent ratio of the respective peak area relative to the total peak area (RPA,\%) and relative to the compound with highest peak area (RPC,\%) for each banana cultivar. Although comparison of GC profiles showed qualitative differences, the quantitative relationship among different compounds in any flavour fraction may have a drastic effect on final aroma. In this sense, the headspace composition of $\mathrm{cv}$. DC showed a richer aroma profile, with a higher number of metabolites contributing to the overall aroma intensity.

According to their chemical structure, the compounds can be classified as monoterpenoids/ $\mathrm{C}_{13}$-norisoprenoids (NMS), higher alcohols (HA), ethyl esters (EE), carbonyl compounds (CC) and furan compounds (FUR). 

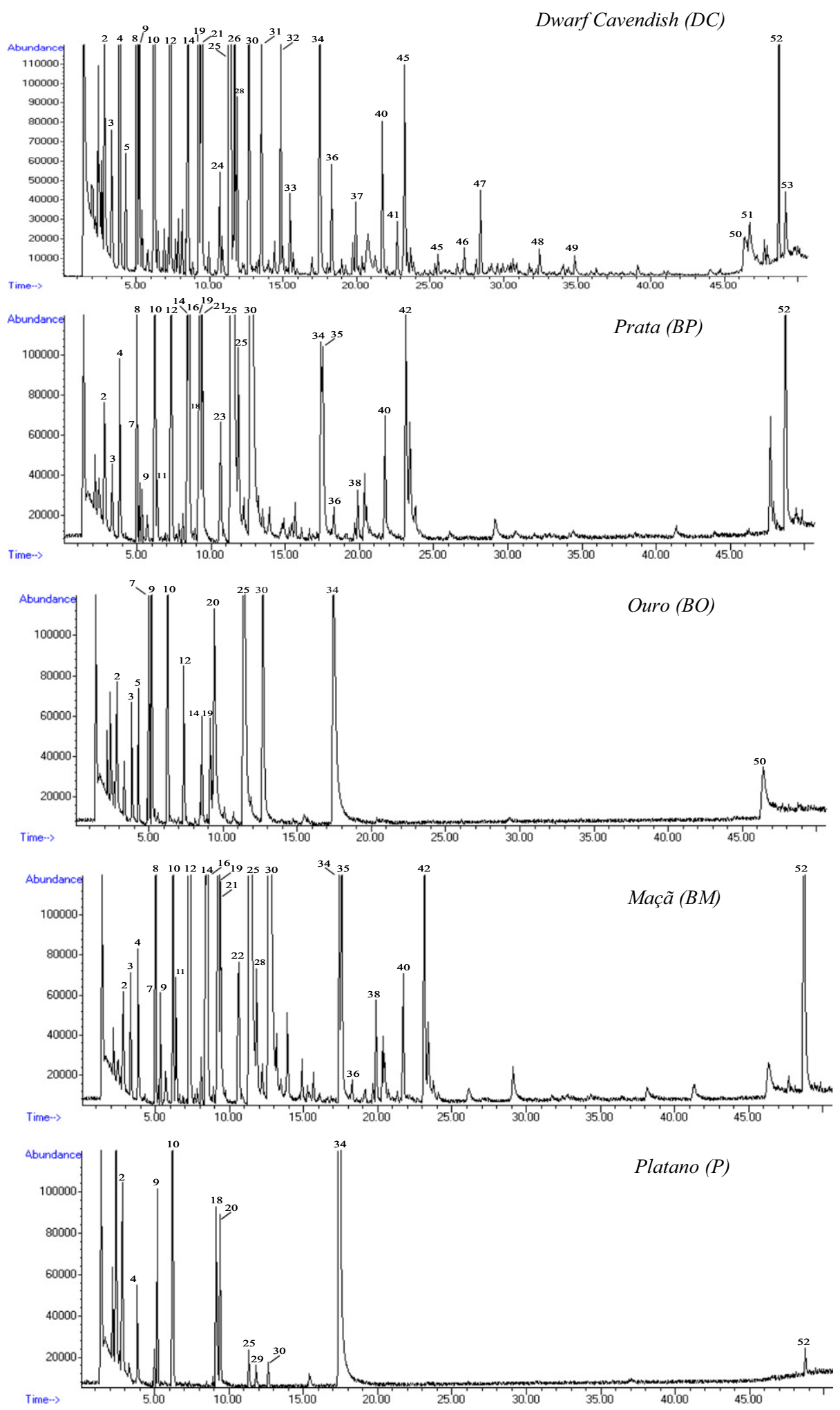

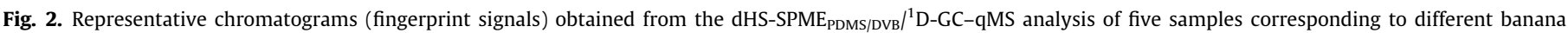

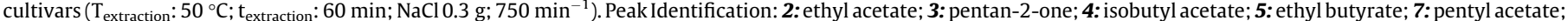

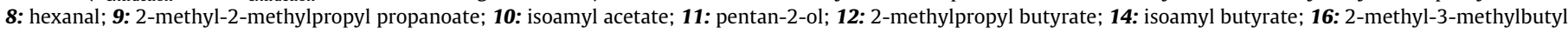

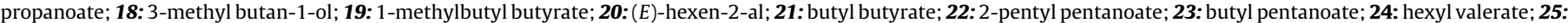

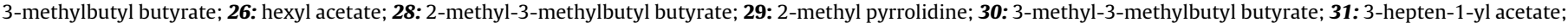

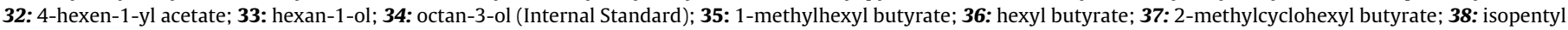

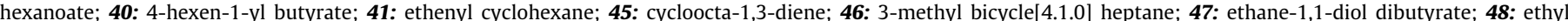

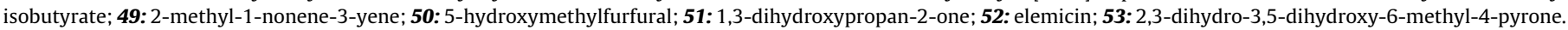


Table 2

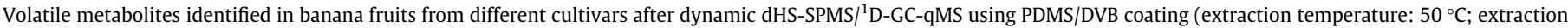
time: $60 \mathrm{~min}$; $750 \mathrm{~min}^{-1} ; 0.3 \mathrm{~g} \mathrm{NaCl}$ ).

\begin{tabular}{|c|c|c|c|c|c|c|c|c|c|c|c|c|c|c|}
\hline \multirow{2}{*}{$\begin{array}{l}\text { Peak } \\
\text { number }\end{array}$} & \multirow[t]{2}{*}{$\mathrm{RT}(\min )$} & \multirow[t]{2}{*}{ RI } & \multirow[t]{2}{*}{ Metabolite } & \multirow[t]{2}{*}{$\mathrm{ID}^{\mathrm{a}}$} & \multicolumn{5}{|c|}{$\%$ of relative areas achieved in different samples ${ }^{b}$} & \multicolumn{5}{|c|}{ RPC (\%) } \\
\hline & & & & & $\mathrm{DC}$ & $\mathrm{BP}$ & BO & $\mathrm{BM}$ & $\mathrm{P}$ & DC & $\mathrm{BP}$ & BO & $\mathrm{BM}$ & $\mathrm{P}$ \\
\hline 2 & 2.408 & 906 & Ethyl acetate & S, MS & 0.82 & - & 4.64 & - & 19.59 & 36 & - & 45 & - & 100 \\
\hline & 3.193 & 969 & n-Propyl acetate & S, MS & - & - & - & - & 1.87 & - & - & - & - & 100 \\
\hline 3 & 3.333 & 979 & Pentan-2-one & S, MS & 0.93 & 0.34 & 1.98 & 0.36 & - & 100 & 61 & 47 & 67 & - \\
\hline 4 & 3.882 & 1013 & Isobutyl acetate & S, MS & 4.73 & 0.57 & - & 0.31 & 3.46 & 100 & 20 & - & 12 & 8 \\
\hline 5 & 4.287 & 1035 & Ethyl butyrate & S, MS & 0.54 & - & 2.47 & - & - & 99 & - & 100 & - & - \\
\hline & 4.883 & 1064 & 3-Methylethyl butyrate & S, MS & - & - & 0.68 & - & - & - & - & 100 & - & - \\
\hline & 4.915 & 1066 & Butyl acetate & S, MS & 5.34 & - & - & - & 0.36 & 100 & - & - & - & 2 \\
\hline 7 & 4.971 & 1068 & 2-Pentyl acetate & S, MS & - & 0.73 & 1.72 & 0.56 & - & - & 100 & 31 & 79 & - \\
\hline 8 & 5.173 & 1079 & Hexanal & S, MS & 1.70 & 0.18 & 5.91 & 0.03 & 8.63 & 100 & 18 & 76 & 3 & 58 \\
\hline 9 & 5.399 & 1087 & MMPP & MS & 0.26 & 0.12 & - & 0.21 & - & 70 & 55 & - & 100 & - \\
\hline & 5.677 & 1098 & 2-Methyl propan-1-ol & S, MS & 0.22 & 0.15 & - & 0.15 & - & 84 & 97 & - & 100 & - \\
\hline 10 & 6.258 & 1120 & Isoamyl acetate & S, MS & 19.34 & 2.52 & 1.77 & 0.21 & 27.61 & 100 & 22 & 2 & 2 & 16 \\
\hline 11 & 6.360 & 1124 & Pentan-2-ol & S, MS & - & 0.22 & - & 0.39 & - & - & 55 & - & 100 & \\
\hline & 6.971 & 1144 & Butyl isobutyrate & MS & 0.18 & - & - & - & - & 100 & - & - & - & - \\
\hline & 7.062 & 1147 & Butan-1-ol & S, MS & 0.18 & - & - & - & - & 100 & - & - & - & - \\
\hline 12 & 7.386 & 1157 & 2-Methylpropyl butyrate & MS & 5.66 & 3.40 & 3.15 & 2.88 & - & 99 & 100 & 12 & 88 & - \\
\hline & 7.925 & 1173 & $2 \mathrm{M} 2 \mathrm{MPB}^{\mathrm{d}}$ & MS & 0.22 & 0.07 & - & 0.05 & - & 100 & 51 & - & 37 & - \\
\hline & 8.135 & 1179 & Heptan-2-one & S, MS & 0.29 & 0.12 & - & 0.14 & - & 100 & 70 & - & 84 & - \\
\hline 14 & 8.481 & 1188 & Isoamyl butyrate & MS & 2.71 & 2.55 & 2.78 & 0.88 & - & 7 & 100 & 2 & 36 & - \\
\hline 16 & 8.582 & 1191 & $\mathrm{MMPB}^{\mathrm{e}}$ & MS & 1.43 & 0.34 & 2.44 & 2.53 & 0.86 & 32 & 36 & 12 & 100 & 2 \\
\hline 18 & 9.142 & 1203 & 3-Methyl butan-1-ol & S, MS & - & 2.55 & 3.56 & - & 11.41 & - & 100 & 18 & - & 28 \\
\hline 19 & 9.334 & 1206 & 1-Methylbutyl butyrate & MS & 3.95 & 3.48 & 1.40 & 8.16 & - & 28 & 41 & 2 & 100 & \\
\hline 20 & 9.406 & 1207 & (E)-hexen-2-al & S, MS & - & - & 11.81 & - & 11.48 & - & - & 100 & - & 51 \\
\hline 21 & 9.494 & 1209 & n-Butyl butyrate & S, MS & 7.41 & 1.09 & - & 0.90 & - & 100 & 25 & - & 21 & - \\
\hline & 10.017 & 1216 & 2-Methylpentyl butyrate & S, MS & 0.16 & - & - & - & - & 100 & - & - & - & - \\
\hline 22 & 10.560 & 1224 & 2-Pentyl pentanoate & S, MS & - & - & - & 0.33 & - & - & - & - & 100 & - \\
\hline 23 & 10.635 & 1225 & n-Butyl pentanoate & S, MS & - & 0.59 & - & - & - & - & 100 & - & - & - \\
\hline 24 & 10.639 & 1225 & Hexyl $n$-valerate & S, MS & 0.33 & - & - & - & - & - & - & - & 100 & - \\
\hline 25 & 11.394 & 1235 & 3-Methylbutyl butyrate & S, MS & 28.30 & 37.85 & 50.01 & 34.35 & - & 1 & 100 & 17 & 55 & - \\
\hline 26 & 11.746 & 1239 & Hexyl acetate & S, MS & 1.53 & - & - & - & - & 100 & - & - & - & - \\
\hline & 11.832 & 1240 & $\mathrm{DMEHP}^{\mathrm{f}}$ & MS & - & 0.92 & - & - & - & - & 100 & - & - & - \\
\hline 28 & 11.920 & 1241 & $\mathrm{MMBB}^{\mathrm{g}}$ & MS & 0.93 & - & - & 0.46 & - & 100 & - & - & 87 & - \\
\hline 29 & 11.932 & 1240 & 2-Methyl pyrrolidine & MS & - & - & - & - & 0.59 & - & - & - & - & 100 \\
\hline 30 & 12.730 & 1251 & $3 \mathrm{M} 3 \mathrm{MBB}^{\mathrm{h}}$ & MS & 2.75 & 32.02 & 4.57 & 34.23 & 0.88 & 5 & 90 & 2 & 100 & 5 \\
\hline & 13.152 & 1256 & 2-Methylbutyl butyrate & S, MS & - & - & - & 0.32 & - & - & - & - & 100 & - \\
\hline 31 & 13.544 & 1260 & 3-Hepten-1-yl acetate & S, MS & 1.45 & - & - & - & - & 100 & - & - & - & - \\
\hline & 13.907 & 1264 & Heptan-2-ol & S, MS & - & 0.27 & - & 0.34 & - & - & 76 & - & 100 & - \\
\hline 32 & 14.865 & 1273 & 4-Hexen-1-yl acetate & S, MS & 1.38 & - & - & - & - & 100 & - & - & - & - \\
\hline & 15.26 & 1277 & Butyl hexanoate & S, MS & - & - & - & 0.05 & - & - & - & - & 100 & - \\
\hline 33 & 15.466 & 1279 & Hexan-1-ol & S, MS & 0.49 & - & - & - & - & 100 & - & - & - & - \\
\hline & 15.643 & 1281 & $3 \mathrm{M} 2 \mathrm{MBB}^{\mathrm{i}}$ & MS & - & 0.19 & - & - & - & - & 100 & - & - & - \\
\hline & 15.731 & 1281 & 3-Methylbutyl pentanoate & MS & 0.13 & - & - & 0.10 & - & 72 & - & - & 100 & - \\
\hline 35 & 17.526 & 1297 & 1-Methylhexyl butyrate & MS & - & 1.27 & - & 1.97 & - & - & 62 & - & 100 & - \\
\hline & 17.999 & 1402 & (E)-2-hexen-1-ol & S, MS & 0.08 & - & - & - & - & 100 & - & - & - & - \\
\hline 36 & 18.343 & 1410 & Hexyl butyrate & S, MS & 0.60 & 0.22 & - & 0.12 & - & 100 & 63 & - & 34 & - \\
\hline & 18.986 & 1424 & (E)-3-hexen-1-ol & S, MS & 0.09 & - & - & - & - & 100 & - & - & - & - \\
\hline & 19.791 & 1442 & 3-Methylhexyl butyrate & MS & 0.19 & 0.08 & - & 0.09 & - & 100 & 72 & - & 89 & - \\
\hline & 19.879 & 1443 & 3-Methyl cyclohexanol & S, MS & - & 0.22 & - & 0.46 & - & - & 45 & - & 100 & - \\
\hline 37 & 19.987 & 1446 & $\mathrm{MCHB}^{\mathrm{j}}$ butyrate & MS & 0.42 & - & - & - & - & 100 & - & - & - & - \\
\hline 38 & 20.428 & 1455 & Isopentyl hexanoate & S, MS & 0.11 & 0.29 & - & 0.33 & - & 20 & 85 & - & 100 & - \\
\hline & 20.627 & 1459 & Furfural & S, MS & 0.36 & - & - & - & - & 100 & - & - & - & - \\
\hline 40 & 21.791 & 1482 & 4-Hexen-1-yl butyrate & S, MS & 0.98 & 0.66 & - & 0.66 & - & 85 & 97 & - & 100 & - \\
\hline 41 & 22.794 & 1500 & Ethenyl cyclohexane & MS & 0.33 & - & - & - & - & 100 & - & - & - & - \\
\hline & 23.118 & 1508 & 4-Hexen-1-yl pentanoate & MS & - & 1.24 & - & 1.61 & - & - & 74 & - & 100 & - \\
\hline 42 & 23.383 & 1514 & Linalool & S, MS & - & 0.79 & - & 0.45 & - & - & 100 & - & 59 & - \\
\hline & 23.504 & 1517 & Heptan-4-one & S, MS & 0.19 & - & - & 0.26 & - & 42 & - & - & 100 & - \\
\hline & 23.629 & 1524 & Cyclooctene & MS & 0.18 & - & - & - & - & 100 & - & - & - & - \\
\hline & 23.736 & 1531 & (Z)-2-hexenyl butyrate & MS & - & 0.26 & - & 0.36 & - & - & 70 & - & 100 & - \\
\hline 45 & 25.553 & 1559 & Cycloocta-1,3-diene & S, MS & 0.13 & - & - & - & - & 100 & - & - & - & - \\
\hline 46 & 27.312 & 1594 & $\mathrm{MBCH}^{1}$ & MS & 0.22 & - & - & - & - & 100 & - & - & - & - \\
\hline 47 & 28.439 & 1618 & $2 \mathrm{M} 1 \mathrm{MBP}^{\mathrm{m}}$ & S, MS & 0.60 & - & - & - & - & 100 & - & - & - & - \\
\hline 48 & 32.414 & 1702 & $\mathrm{MEP}^{\mathrm{n}}$ & S, MS & 0.22 & - & - & - & - & 100 & - & - & - & - \\
\hline & 46.312 & 2028 & Octanoic acid & S, MS & 0.28 & - & - & - & - & 100 & - & - & - & - \\
\hline 50 & 46.43 & 2030 & 5-Hydroxymethylfurfural & S, MS & 0.67 & - & 3.54 & - & 11.74 & 49 & - & 58 & - & 100 \\
\hline 51 & 47.725 & 2059 & $\mathrm{DHP}^{\mathrm{o}}$ & MS & - & 0.66 & - & - & - & - & 100 & - & - & - \\
\hline & 47.907 & 2063 & Eugenol & S, MS & 0.64 & 0.13 & - & - & - & 100 & 34 & - & - & - \\
\hline 52 & 48.695 & 2080 & Elemicin & MS & 1.61 & 3.27 & - & 5.41 & 1.73 & 17 & 58 & - & 100 & 2 \\
\hline 53 & 49.156 & 2090 & $\mathrm{DDMP}^{\mathrm{p}}$ & MS & 0.09 & - & - & - & - & 100 & - & - & - & - \\
\hline
\end{tabular}


Table 2 (continued)

\begin{tabular}{|c|c|c|c|c|c|c|c|c|c|c|c|c|c|c|}
\hline \multirow{2}{*}{$\begin{array}{l}\text { Peak } \\
\text { number }\end{array}$} & \multirow[t]{2}{*}{ RT (min) } & \multirow[t]{2}{*}{ RI } & \multirow[t]{2}{*}{ Metabolite } & \multirow[t]{2}{*}{$\mathrm{ID}^{\mathrm{a}}$} & \multicolumn{5}{|c|}{$\%$ of relative areas achieved in different samples ${ }^{\mathrm{b}}$} & \multicolumn{5}{|c|}{ RPC (\%) } \\
\hline & & & & & DC & $\mathrm{BP}$ & BO & BM & $\mathrm{P}$ & $\mathrm{DC}$ & $\mathrm{BP}$ & BO & $\mathrm{BM}$ & $\mathrm{P}$ \\
\hline & $\begin{array}{l}\text { Total compounds } \\
\text { identified in } \\
\text { banana fruit }\end{array}$ & & & & & & & & & 51 & 34 & 16 & 35 & 13 \\
\hline & Sum of total area & & $3.93 E+08$ & & $3.93 E+08$ & $6.61 \mathrm{E}+08$ & $8.62 \mathrm{E}+07$ & $6.88 \mathrm{E}+08$ & $4.52 \mathrm{E}+07$ & & & & & \\
\hline & $\% \operatorname{RSD}(n=4)$ & & 5.25 & & 5.25 & 1.64 & 2.66 & 5.19 & 0.32 & & & & & \\
\hline
\end{tabular}

${ }^{\text {a }}$ ID: reliability of identification: S-standard, MS-mass spectrum.

b DC-Dwarf Cavendish; BP-Prata; BO-Ouro;BM-Maçã;P-Plátano.

c MMPP: 2-methyl-2-methylpropyl propanoate.

d 2M2MPB: 2-methyl-2-methylpropyl butyrate.

e MMBP: 2-methyl-3-methylbutyl propanoate.

f DMEHP: 2,2-dimethyl-2-ethylhexyl propanoate.

g MMBB: 2-methyl-3-methylbutyl butyrate.

h 3M3MBB: 3-methyl-3-methylbutyl butyrate.

i 3M2MBB: 3-methyl-2-methylbutyl butyrate.

j MCHB: cis-2-methylcyclohexyl butyrate.

${ }^{1} \mathrm{MBCH}$ : 3-methyl-bicyclo[4.1.0]heptane.

m 2M1MBP: 2-methyl-1-methylbutyl propanoate.

${ }^{n}$ MEP: 2-methylethyl propanoate.

${ }^{\circ} \mathrm{DHP}^{\mathrm{o}} 1,3$-dihydroxy propan-2-one.

p DDMP: 2,3-dihydro-3,5-dihydroxy-6-methyl-4H-pyran-4-one.
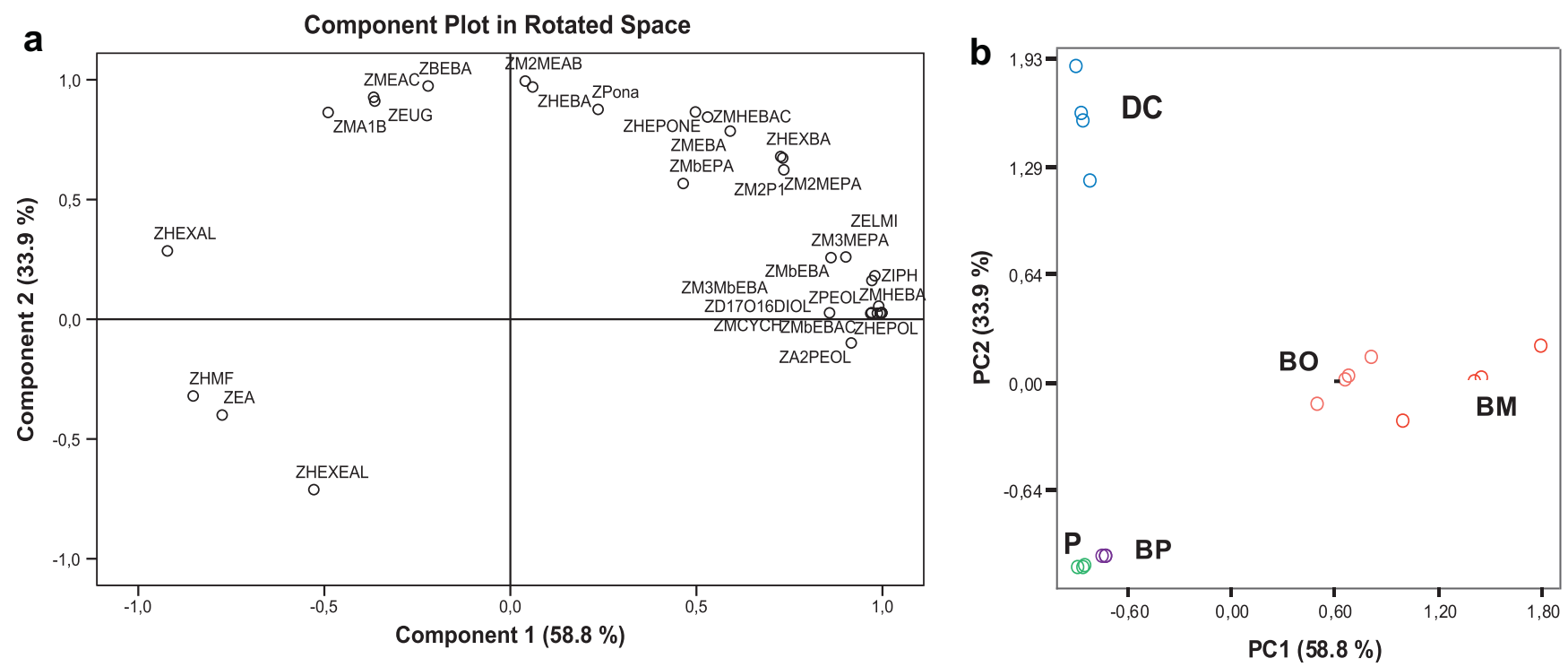

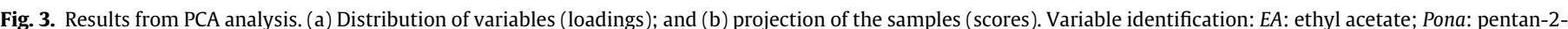

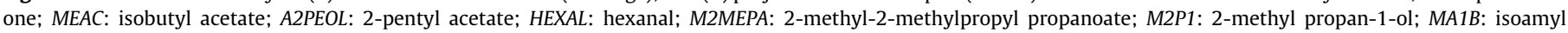

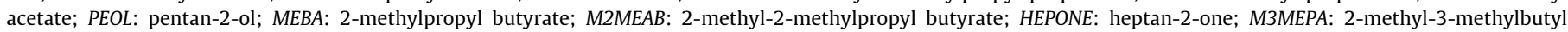

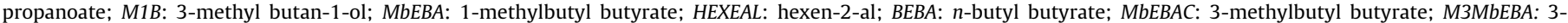

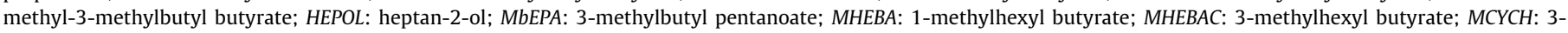
methyl cyclohexanol; IPH: isopentyl hexanoate; HEXBA: (Z)-2-hexenyl butyrate; D17016DIOL; linalool; HMF: 5-hydroxymethylfurfural; EUG: eugenol; ELMI: elemicin.

The highest amount of volatile metabolites was obtained in bananas from Prata and Maçã cultivars, followed by Dwarf Cavendish and Ouro cultivars. Contrarily bananas from Platano cultivar was found to had the lowest content of volatiles. Only four volatile metabolites among the total of 68 identified were found to be common to all studied cultivars: hexanal, isoamyl acetate, 2methyl-3-methylbutyl propanoate and 3-methyl-3-methylbutyl butyrate (Table 2). Isoamyl acetate, considered the character impact metabolite in banana flavour (Nogueira, Fernandes, \& Nascimento, 2003), is one of the few metabolites present in a higher amount in banana, mainly from Dwarf Cavendish and Platano cultivars, while other short esters such as butyl acetate, with a fruity-estery odour description, are present only at low levels.
With exception of bananas from Platano cultivar, characterised by high levels of higher alcohols (54.6\%), all other banana cultivars were largely dominated by ethyl esters which accounted for $90.1 \%$, 86.5\%, 80.9\% and 51.2\% in Maçã, Prata, Dwarf Cavendish and Ouro total GC peak areas, respectively. Carbonyl compounds followed by higher alcohols were found to be the second and third most abundant chemical groups. These impart green-woody notes that also contributed to banana flavour.

Among volatile metabolites identified in bananas from Dwarf Cavendish cultivar, the most dominant were found to be 3-methylbutyl butyrate, isoamyl acetate, butyl butyrate, 2-methylpropyl butyrate, butyl acetate, isobutyl acetate and 1-methylbutyl butyrate, constituting $72.6 \%$ of the total volatile composition. Banana 
Table 3

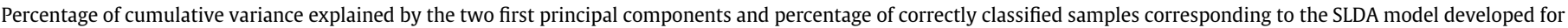
the five-class approach analysed.

\begin{tabular}{|c|c|c|c|c|c|c|c|c|}
\hline \multirow[t]{2}{*}{ Component } & \multicolumn{4}{|c|}{ Extraction sums of squared loadings } & \multicolumn{4}{|c|}{ Rotation sums of squared loadings } \\
\hline & Total & $\%$ of variance & \multicolumn{2}{|c|}{ Cumulative \% } & Total & \multicolumn{2}{|c|}{$\%$ of variance } & Cumulative \% \\
\hline \multicolumn{9}{|c|}{ Total variance explained } \\
\hline 1 & 20,094 & 62,795 & & & 18,615 & 58,173 & & 58,173 \\
\hline \multirow[t]{3}{*}{2} & 9,366 & 29,269 & & & 10,845 & 33,891 & & 92,064 \\
\hline & & \multirow[t]{2}{*}{ Cultivar } & \multicolumn{5}{|c|}{ Predicted group membership } & \multirow[t]{2}{*}{ Total } \\
\hline & & & DC & $\mathrm{BP}$ & BO & $\mathrm{BM}$ & $\mathrm{P}$ & \\
\hline \multicolumn{9}{|c|}{ Classification results ${ }^{\mathrm{b}, \mathrm{c}}$} \\
\hline \multirow[t]{10}{*}{ Original } & \multirow[t]{5}{*}{ Count } & DC & 4 & 0 & 0 & 0 & 0 & 4 \\
\hline & & $\mathrm{BP}$ & 0 & 4 & 0 & 0 & 0 & 4 \\
\hline & & $\mathrm{BO}$ & 0 & 0 & 4 & 0 & 0 & 4 \\
\hline & & BM & 0 & 0 & 0 & 4 & 0 & 4 \\
\hline & & $\mathrm{P}$ & 0 & 0 & 0 & 0 & 4 & 4 \\
\hline & \multirow[t]{5}{*}{$\%$} & DC & 100.0 & .0 & .0 & .0 & .0 & 100.0 \\
\hline & & $\mathrm{BP}$ & .0 & 100.0 & .0 & .0 & .0 & 100.0 \\
\hline & & BO & .0 & .0 & 100.0 & .0 & .0 & 100.0 \\
\hline & & $\mathrm{BM}$ & .0 & .0 & .0 & 100.0 & .0 & 100.0 \\
\hline & & $\mathrm{P}$ & .0 & .0 & .0 & .0 & 100.0 & 100.0 \\
\hline \multirow[t]{10}{*}{ Cross-validated $^{\mathrm{a}}$} & \multirow[t]{5}{*}{ Count } & DC & 4 & 0 & 0 & 0 & 0 & 4 \\
\hline & & $\mathrm{BP}$ & 0 & 4 & 0 & 0 & 0 & 4 \\
\hline & & BO & 0 & 0 & 3 & 1 & 0 & 4 \\
\hline & & $\mathrm{BM}$ & 0 & 0 & 0 & 4 & 0 & 4 \\
\hline & & $\mathrm{P}$ & 0 & 0 & 0 & 1 & 3 & 4 \\
\hline & \multirow[t]{5}{*}{$\%$} & DC & 100.0 & .0 & .0 & .0 & .0 & 100.0 \\
\hline & & BP & .0 & 100.0 & .0 & .0 & .0 & 100.0 \\
\hline & & BO & .0 & .0 & 75.0 & 25.0 & .0 & 100.0 \\
\hline & & $\mathrm{BM}$ & .0 & .0 & .0 & 100.0 & .0 & 100.0 \\
\hline & & $\mathrm{P}$ & .0 & .0 & .0 & 25.0 & 75,0 & 100.0 \\
\hline
\end{tabular}

Extraction method: principal component analysis.

a Cross validation is done only for those cases in the analysis. In cross validation, each case is classified by the functions derived from all cases other than that case.

b $100.0 \%$ of original grouped cases correctly classified.

c $90.0 \%$ of cross-validated grouped cases correctly classified.

samples from Prata cultivar contained 3-methylbutyl butyrate, 3-methyl-3-methylbutyl butyrate, 1-methylbutyl butyrate, 2methylpropyl butyrate, elemicin, 3-methyl butan-1-ol, isoamyl butyrate and isoamyl acetate, as the main volatile metabolites, whereas bananas from Ouro cultivars are largely dominated by 3 -methylbutyl butyrate and hexen-2-al, accounting for $54.4 \%$ of the total volatile fraction. Other compounds, such as hexanal, 3methyl-3-methylbutyl butyrate, ethyl acetate, isoamyl acetate and 3-methyl butan-1-ol, were also present at high levels. It is important to emphasise the lack of elemicin in this banana variety. Table 2 illustrates that 35 volatile metabolites were identified in banana samples from Maçã cultivar, from which 24 tentatively identified, being a large number of them esters and carbonyl compounds. 3-Methylbutyl butyrate, 3-methyl-3-methylbutyl butyrate, and 1-methylbutyl butyrate, were the most abundant metabolites identified in these samples. Bananas from this cultivar are very rich in elemicin, in comparison to all other studied cultivars. In banana samples from Platano cultivar only 13 VOMs were identified being the higher alcohols and carbonyl compounds the most dominant groups. Isoamyl acetate and ethyl acetate were the major components. Other representative metabolites of this banana variety were identified as 5-hydroxymethylfurfural, (E)-hexen-2-al, 3-methylbutan-1-ol, and hexanal.

Some metabolites identified in the investigated banana varieties, like butyl acetate, hexan-1-ol, 3-methylbutyl butyrate and hexyl butyrate (Nogueira et al., 2003), 1-methylhexyl butyrate, 3methylbutyl butyrate and octanoic acid (Wang, Li, Chen, Bao, \& Yang, 2007), 3-methylbutan-1-ol and eugenol (Miranda, Nogueira, Pontes, \& Rezende, 2001; Nogueira et al., 2003), butan-1-ol and hexanal (Mui, Durance, \& Scaman, 2002; Nogueira et al., 2003), isobutyl acetate and pentan-2-one (Salmon, Martin, Remaud, \& Fourel, 1996), isoamyl acetate (Mui et al., 2002; Salmon et al., 1996) and isoamyl butyrate (Boudhrioua et al., 2003; Brat et al., 2004;
Mui et al., 2002; Salmon et al., 1996; Wang et al., 2007), have been reported as common components of several banana varieties. According to some authors, the banana aroma was particularly associated with methyl, 3-methylbutyl, 2-methylpropyl and isoamyl esters of acetic, propanoic and butanoic acids. However, the volatile fraction produced by bananas from Dwarf Cavendish, Prata, Ouro and Maçã cultivars, is dominated by 3-methylbutyl butyrate which account for $28.3 \%, 37.8 \%, 50.0 \%$ and $34.5 \%$, respectively, of total GC peak area, whereas isoamyl acetate (27.6\%) present the highest level in bananas from Platano cultivar. In addition, Maçã and Prata banana varieties are richer in ethyl esters, carbonyl compounds and monoterpenoids, than Ouro, Dwarf Cavendish and Platano bananas (Table 2).

In comparison to banana cultivars from other geographical origins some compositional differences could be observed. Pentan-2one was reported as one of major constituents in several banana cultivars from Spain and Philippines (Salmon et al., 1996; Shiota, 1993), but not in the cultivars investigated in this work. Another interesting difference is the substantial content of eugenol reported in bananas from Spain, Philippines and Latin America (Salmon et al., 1996; Shiota, 1993), which was only identified in banana from Dwarf Cavendish and Prata cultivars.

\subsection{Multivariate analysis}

To summarise graphically the changes in the volatile content in the different cultivars, a principal component analysis (PCA) was successfully applied to the final data set in order to study the main sources of variability between the banana samples from various cultivars and detect the potential relationships/variables responsible for differentiation. The PCA analysis led to the extraction of two principal components (PCs) having the initial eigenvalues $>1$ which contributed to $92.1 \%$ of the total variance of the data set. 
The first principal component (PC1) identified as a linear combination of 3-methylhexyl butyrate (MHEBAC), heptan-2-ol (HEPOL:), isopentyl hexanoate (IPH:) and 2-pentyl acetate (A2PEOL) accounted for $58.2 \%$ of the variance. PC2 explained $33.9 \%$ of the variance and was mainly represented by the linear combination of the following variables: 2-methyl-2-methylpropyl butyrate (M2MEAB), (Z)-2-hexenyl butyrate (HEXBA) and $n$-butyl butyrate (BEBA) (Fig. 3a). The scatter plot of PCA scores corresponding to this discrimination is illustrated in Fig. $3 \mathrm{~b}$.

The first axis (58.2\% of the variance explained), mainly discriminate bananas from Ouro and Maçã cultivars from the others, whereas the second axis (33.9\% of the variance explained) mainly discriminate Dwarf Cavendish from Platano and Prata cultivars. Bananas from Ouro and Maçã cultivars, positively located on the first axis, are particularly characterised by heptan-2-ol, 3-methylbutyl butyrate, 1-methylhexyl butyrate and pentan-2-ol. Dwarf Cavendish positively located on the second axis (PC2) is mainly discriminated among bananas from Prata and Platano cultivars by a greater content of 2-methyl-2-methylpropyl butyrate, butyl butyrate, isobutyl acetate, isoamyl acetate and pentan-2-one. These results clearly demonstrate a clear classification of banana samples according to the cultivars based on volatile metabolites identified in the free fraction. The eigenvalues and explained and accumulated variance of the first five principal components (PCs) are listed in Table 3.

After PCA, stepwise linear discriminant analysis was performed on peak area data in order to highlight the most significant variables in the differentiation between banana cultivars and to find discriminant functions to predict the group to which future samples belonged. The projection of the banana cultivars in twodimensional space, generated by the two first discriminant functions, explain $77.8 \%$ of the total variance.

Four clusters (Dwarf Cavendish and Prata cases are grouped, low Mahlanodis distance) representing each cultivar were observed. The good agreement achieved indicates that very acceptable classification functions can be deduced. The prediction ability of the SLDA model developed was evaluated by leave-oneout cross-validation. Table 3 shows the classification and prediction rates corresponding to the SLDA model developed on the basis of the subset of variables with the largest discriminant power between the five categories selected by the stepwise procedure.

From the obtained results, we can ascertain that dHS-SPME/1DGC-qMS together with a PCA represent a new solution toward fruit cultivar classification through the analysis of their volatile fraction.

\section{Conclusions}

This research consisted in a feasibility study to examine the use of dHS-SPME/1D-GC-qMS in combination with pattern recognition techniques as a simple, fast and reliable classification methodology to objectively discriminate between bananas from different cultivars on the basis of their volatile distinctive profiles. dHS-SPME in combination with gas chromatography-mass spectrometry provides a suitable and selective mean to establish the global volatile signature in different banana cultivars. The optimisation of the significant parameters affecting sorption process such as coating, extraction time and temperature, was done by using univariate experimental design. The chromatographic profile obtained, the total 1D-GC-qMS peak area and the number of identified metabolites, suggest that the PDMS/DVB coating is the most suitable for isolation the VOMs from bananas using the dHS-SPME technique. The optimum set of conditions for the influential parameters was $60 \mathrm{~min}$ and $50^{\circ} \mathrm{C}$ for extraction time and extraction temperature, respectively.

Ethyl esters were found to comprise the largest chemical class in the bananas from studied cultivars, accounting $80.9 \%, 86.5 \%$,
$51.2 \%, 90.1 \%$ and $6.1 \%$ for the volatile fraction in Dwarf Cavendish, Prata, Ouro, Maçã and Platano varieties, respectively. As found for bananas from Ouro cultivar (50.0\%), 3-methylbutyl butyrate was found to be the most abundant volatile metabolite in bananas from Dwarf Cavendish (28.3\%), Prata (37.8\%) and Maçã (34.4\%) cultivars, while isoamyl acetate (27.6\%) occur as the major volatile metabolite in bananas from Platano cultivar.

Finally the acquired data set was submitted to PCA and the corresponding bananas discrimination according to cultivars was successfully established. The application of the SLDA method on the volatile metabolites data set characterised by dHS-SPME/1D-GCqMS resulted in predictive abilities of $90 \%$ as evaluated by the cross-validation procedure. The method could be extended to other fruit species permitting the development of a new tool useful in food quality control.

\section{Acknowledgements}

The authors thanks the financial support of Fundação para a Ciência e Tecnologia (FCT) through MS Portuguese Networks (REDE/1508/RNEM/2005) and Pluriannual base funding (QUI-Madeira-674).

\section{References}

Arias, P., Dankers, C., Liu, P., \& Pilkauskas, P. (2003). The World Banana Economy: 1985-2002 (Vol. 1). Rome: FAO.

Augusto, F., Valente, A. L., dos Santos Tada, E., \& Rivellino, S. R. (2000). Screening of Brazilian fruit aromas using solid-phase microextraction-gas chromatographymass spectrometry. Journal of Chromatography A, 873(1), 117-127.

Bianchi, F., Careri, M., Mangia, A., \& Musci, M. (2007). Retention indices in the analysis of food aroma volatile compounds in temperature-programmed gas chromatography: database creation and evaluation of precision and robustness. Journal of Separation Science, 30(4), 563-572.

Boudhrioua, N., Giampaoli, P., \& Bonazzi, C. (2003). Changes in aromatic components of banana during ripening and air-drying. LebensmittelWissenschaft und -Technologie, 36, 633-642.

Brat, P., Yahia, A., Chillet, M., Bugaud, C., Bakry, F., Reynes, M., et al. (2004). Influence of cultivar, growth altitude and maturity stage on banana volatile compound composition. Fruits, 59(2), 75-82.

Camara, J. S., Alves, M. A., \& Marques, J. C. (2006). Multivariate analysis for the classification and differentiation of Madeira wines according to main grape varieties. Talanta, 68(5), 1512-1521.

Cano, M. P., de Ancos, B., Matallana, M. C., Cámara, M., Reglero, G., \& Tabera, J. (1997). Differences among Spanish and Latin-American banana cultivars: Morphological, chemical and sensory characteristics. Food Chemistry, 59(3), 411-419.

Cheong, K. W., Tan, C. P., Mirhosseini, H., Hamid, N. S. A., Osman, A., \& Basri, M. (2010). Equilibrium headspace analysis of volatile flavour compounds extracted from soursop (Anoan muricata) using solid phase microextraction. Food Research International, 43, 1267-1276.

Chien, Y.-C., Uang, S.-N., Kuo, C.-T., Shih, T.-S., \& Jen, J.-F. (2000). Analytical method for monitoring airborne trimethylamine using solid phase micro-extraction and gas chromatography-flame ionization detection. Analytica Chimica Acta, 419(1), 73-79.

Coelho, E., Perestrelo, R., Neng, N. R., Camara, J. S., Coimbra, M. A., Nogueira, J. M., et al. (2008). Optimisation of stir bar sorptive extraction and liquid desorption combined with large volume injection-gas chromatography-quadrupole mass spectrometry for the determination of volatile compounds in wines. Analytica Chimica Acta, 624(1), 79-89.

Deng, C., Li, N., \& Zhang, X. (2004a). Development of headspace solid-phase microextraction with on-fiber derivatization for determination of hexanal and heptanal in human blood. Journal of Chromatography, B: Analytical Technologies in the Biomedical and Life Sciences, 813(1-2), 47-52.

Deng, C., Zhang, X., \& Li, N. (2004b). Investigation of volatile biomarkers in lung cancer blood using solid-phase microextraction and capillary gas chromatography-mass spectrometry. Journal of Chromatography, B: Analytical Technologies in the Biomedical and Life Sciences, 808(2), 269-277.

Ferreira, L., Perestrelo, R., Caldeira, M., \& Camara, J. S. (2009). Characterization of volatile substances in apples from Rosaceae family by headspace solid-phase microextraction followed by GC-qMS. Journal of Separation Science, 32(11), $1875-1888$.

Forina, M., Armanino, C., Castino, M., \& Ubigli, M. (1986). Multivariate data analysis as a discriminating method of the origin of wines. Vitis, 25, 189-201.

Hognadottir, A., \& Rouseff, R. L. (2003). Identification of aroma active compounds in orange essence oil using gas chromatography-olfactometry and gas chromatography-mass spectrometry. Journal of Chromatography A, 998(1-2), 201-211. 
Ibáñez, E., López-Sebastián, S., Ramos, E., Tabera, J., \& Reglero, G. (1998). Analysis of volatile fruit components by headspace solid-phase microextraction. Food Chemistry, 63, 281-286.

Jordan, M. J., Tandon, K., Shaw, P. E., \& Goodner, K. L. (2001). Aromatic profile of aqueous banana essence and banana fruit by gas chromatography-mass spectrometry (GC-MS) and gas chromatography-olfactometry (GC-O). Journal of Agriculture and Food Chemistry, 49(10), 4813-4817.

Kumazawa, T., Lee, X., Sato, K., \& Suzuki, O. (2003). Analytica Chimica Acta, 492(1-2), 49-67.

Lambropoulou, D. A., \& Albanis, T. A. (2001). Optimization of headspace solid-phase microextraction conditions for the determination of organophosphorus insecticides in natural waters. Journal of Chromatography A, 922(1-2), 243-255.

Mayr, D., Märk, T., Lindinger, W., Brevard, H., \& Yeretzian, C. (2003). Breath-bybreath analysis of banana aroma by proton transfer reaction mass spectrometry. International Journal of Mass Spectrometry, 223-224, 743-756.

Mendes, B., Gonçalves, G., \& Câmara, J. S. (2012). Effectiveness of high-throughput miniaturized sorbent- and solid phase microextraction techniques combined with gas chromatography-mass spectrometry analysis to obtain a rapid screening of volatile and semi-volatile composition of wines - A comparative study. Talanta, 88, 79-94.

Miranda, E., Nogueira, R., Pontes, S., \& Rezende, C. (2001). Odour-active compounds of banana passa identified by aroma extract dilution analysis. Flavour and Fragrance Journal, 16, 281-285.

Moeder, M., Schrader, S., Winkler, M., \& Popp, P. (2000). Solid-phase microextractiongas chromatography-mass spectrometry of biologically active substances in water samples. Journal of Chromatography A, 873(1), 95-106.

Mui, W. W., Durance, T. D., \& Scaman, C. H. (2002). Flavor and texture of banana chips dried by combinations of hot air, vacuum, and microwave processing. Journal of Agriculture and Food Chemistry, 50(7), 1883-1889.

Navarro, T., De Lorenzo, C., \& Perez, R. A. (2004). SPME analysis of volatile compounds from unfermented olives subjected to thermal treatment. Analytical and Bioanalytical Chemistry, 379(5-6), 812-817.

Nogueira, J. M., Fernandes, P. J., \& Nascimento, A. M. (2003). Composition of volatiles of banana cultivars from Madeira Island. Phytochemical Analysis, 14(2), 87-90.

Pereira, J., Pereira, J. M., \& Câmara, J. S. (2011). Effectiveness of different solid-phase microextraction fibres for distinction of selected Madeira island fruits based on their volatile metabolite profile - identification of novel compounds. Talanta, 83, 899-906.

Perestrelo, R., Caldeira, M., Rodrigues, F., \& Camara, J. S. (2008). Volatile flavour constituent patterns of Terras Madeirenses red wines extracted by dynamic headspace solid-phase microextraction. Journal of Separation Science, 31(10), $1841-1850$

Perestrelo, R., Nogueira, J. M., \& Camara, J. S. (2009). Potentialities of two solventless extraction approaches-stir bar sorptive extraction and headspace solid-phase microextraction for determination of higher alcohol acetates, isoamyl esters and ethyl esters in wines. Talanta, 80(2), 622-630.

Perez, A. G., Olias, R., Luaces, P., \& Sanz, C. (2002). Biosynthesis of strawberry aroma compounds through amino acid metabolism. Journal of Agriculture and Food Chemistry, 50(14), 4037-4042.
Powers, J., \& Keith, E. (1968). Stepwise discriminant analysis of gaschromatographic data as an aid in classifying the flavor quality of foods. Journal of Food Science, 36, 207-213.

Pozo, B., Pueyo, E., Martin-Alvarez, P. J., \& Polo, M. C. (2001). Polydimethylsiloxane solid-phase microextraction-gas chromatography method for the analysis of volatile compounds in wines. Its application to the characterization of varietal wines. Journal of Chromatography A, 922(1-2), 267-275.

Risticevic, S., Carasek, E., \& Pawliszyn, J. (2008). Headspace solid-phase microextraction-gas chromatographic-time-of-flight mass spectrometric methodology for geographical origin verification of coffee. Analytica Chimica Acta, 617(1-2), 72-84.

Salmon, B., Martin, G. J., Remaud, G., \& Fourel, F. (1996). Compositional and isotopic studies of fruit flavours. Part I. The banana aroma compositional and isotopic studies of fruit flavours. Part I. The banana aroma. Flavour and Fragrance Journal, $11,353-359$

Shiota, H. (1993). New ester components in the volatiles of banana fruit (Musa sapientum L.). Journal of Agriculture and Food Chemistry, 41, 2056-2062.

Silva, C. L., Passos, M., \& Câmara, J. S. (2011). Investigation of urinary volatile organic metabolites as potential cancer biomarkers by solid-phase microextraction combined with gas chromatography-mass spectrometry methodology. British Cancer Journal, 105, 1894-1904.

Silva, C. L., Passos, M., \& Câmara, J. S. (2012). Solid phase microextraction, mass spectrometry and metabolomics approaches for detection of urinary cancer biomarkers - a potential strategy for diagnosing breast cancer diagnosis. Talanta, 89, 360-368.

Ternes, T. (1998). Occurrence of drugs in German sewage treatment plants and rivers. Water Research, 32, 3245.

Tressl, R., \& Albrecht, W. (1985). Biogeneration of Aromas. In T. H. P. A. R. Croteau (Ed.), Biogenesis of Aroma Compounds Through Acyl Pathways, (pp. 114-133).

Tressl, R., \& Drawert, F. (1973). Biogenesis of banana volatiles. Journal of Agriculture and Food Chemistry, 21, 560-565.

Van Den Dool, H., \& Kratz, P. D. (1963). A generalization of the retention index system including linear temperature programmed gas-liquid partition chromatography. Journal of Chromatography A, 11, 463-471.

Vermeir, S., Hertog, M. L. A. T. M., Vankerschaver, K., Swennen, R., Nicolaï, B. M., \& Lammertyn, J. (2009). Instrumental based flavour characterisation of banana fruit. LWT - Food Science and Technology, 42(10), 1647-1653.

Wang, J., Li, Y., Chen, R., Bao, J., \& Yang, G. (2007). Comparison of volatiles of banana powder dehydrated by vacuum belt drying freeze-drying and air-drying. Food Chemistry, 104, 1516-1521.

Wyllie, S. G., \& Fellman, J. K. (2000). Formation of volatile branched chain esters in bananas (Musa sapientum L.). Journal of Agriculture and Food Chemistry, 48(8), 3493-3496.

Yoshioka, H., Ueda, Y., \& Iwata, T. (1982). Physiological studies of fruit ripening in relation to heat injury. IV. Development of isoamyl acetate biosynthetic pathway in banana fruit during ripening and suppression of its development at high temperature. Nippon Shokuhin Kogyo Gakkaishi, 29, 333-339. 